ORIGINAL ARTICLE

\title{
Increases in booster seat use among children of low income families and variation with age
}

\author{
R Apsler, S W Formica, A F Rosenthal, K Robinson
}

Injury Prevention 2003;9:322-325

\begin{abstract}
Objectives: To increase booster seat use among low income parents.
Design/methods: A pre-test/post-test design conducted in nine daycare centers with post-test observations four to eight weeks after the intervention.

Intervention: Parents who participated in an educational training received free seats, educational programs were provided to all daycare staff and children, and signs in parking lots informed parents about child restraints. At seven centers, new policies recommended compliance with state restraint laws. Parents at four centers randomly chosen from the seven received financial incentives if observed using booster seats.

Main outcome measure: The percent of children aged 4-8 riding in booster seats.

Results: Pre-test observations of $1854-8$ year olds found $56 \%$ riding unrestrained and fewer than $3 \%$ riding in booster seats. After the intervention, observation of 146 children found the number riding in booster seats increased to $38 \%$ and the number observed without restraints decreased to $26 \%$. Most booster seat use occurred with 4 and 5 year olds. No 7 or 8 year olds rode in booster seats. Changing center policies to recommend compliance with state restraint laws and an offer of financial incentives appeared to have no additional impact.

Conclusions: Booster seat usage among low income families can be increased dramatically, though use decreases with age. Providing free seats accompanied by training may be sufficient without the need for additional intervention.
\end{abstract}

See end of article for authors' affiliations

Dr Robert Apsler, 84 Mill

Street, Lincoln, MA 01773

1706, USA; rapsler@

mail2.gis.net

B

ooster seats, vehicle child restraints that position small children who have outgrown child safety seats so that standard seatbelts can protect them more effectively, are the recommended restraint system for children over 40 pounds $(18.2 \mathrm{~kg})$ in weight and less than 57 inches in height $(144.8 \mathrm{~cm}){ }^{1-4}$ These parameters encompass many children between the ages of 4 and 8 years of age who do not always fit properly in adult lap/shoulder belts unless they are elevated with the assistance of a booster seat. ${ }^{2}$ Nonetheless, studies have found that only about 5\% of parents with children aged 4-8 use booster seats. ${ }^{56}$ A more recent survey found increased use over the last two years, though the authors caution that their data are based on telephone reports from drivers of vehicles in which children were injured and may be biased by "over-reporting of restraint use $^{\prime \prime} .{ }^{7}$

Motor vehicle crashes kill more children in the 4-8 age group-roughly 500 children between 1994 and 1998-than any other source of unintentional injury. ${ }^{8}$ In 2000 , nearly half of the 4-8 year olds killed in crashes were unrestrained.' Wearing adult seatbelts in the back seat or using a belt positioning booster seat greatly reduces the risk of fatality to 4-8 year olds. ${ }^{9}$ However, a recent survey of parents of 4243 children involved in crashes found that for 4-7 year olds, the odds of injury were $59 \%$ lower when riding in belt positioning booster seats than when using seatbelts alone. ${ }^{10}$

Instances of premature use of adult seatbelts, failure to use booster seats, and the absence of any restraints increases with age for children 4-8 years old. One study observed use of booster seats by 125 children aged 4-8 and found a dramatic decrease in usage with age. The percent of children observed riding in booster seats was highest for 4 year olds (33\%) and dropped to just $10 \%$ for $6-8$ year olds. ${ }^{11}$ In another study, nearly all (95\%) of the 8344 injured children in the sample were restrained, according to their parents, but many children were placed prematurely in booster seats or seatbelts. In fact, booster seat use reached its zenith at age 3 (29\% reported use) and then dropped each following year to the point that fewer than $1 \%$ of children in crashes aged 5-8 were reported to have been properly restrained in booster seats when injured. ${ }^{12}$

Increasing appropriate use of booster seats among 4-8 year olds constitutes a significant challenge. Two research teams conducted focus groups with parents and found many confused by the age and height guidelines regarding booster seat use. These parents also indicated that the cost of purchasing seats and resistance from children were barriers to use. ${ }^{13} 14$

Most efforts to increase the use of child restraints have focused on child safety seat use by children under the ages of 5 or $6 .^{15-19}$ One study employed a public information campaign and targeted a wider age range but failed to increase use of restraints by children between the ages of 5 and $11-$ a range that includes $5-8$ year olds who should be riding in booster seats. ${ }^{20} \mathrm{~A}$ recent, multifaceted community education campaign targeted booster seats directly and succeeded in significantly increasing use. Most of the effect was on 4-6 year olds with little impact on 7 or 8 year olds. ${ }^{21}$

The Providence Safe Communities Partnership, an injury prevention coalition, responded to the problem of unrestrained 4-8 year olds with an intervention aimed at increasing booster seat use among low income parents with children in daycare centers. A pre-test/post-test design studied the impact of providing parents with free booster seats accompanied by three levels of additional influence.

\section{METHODS}

The study was conducted in nine daycare centers, none of which were Headstart centers, located within the portion of Providence, Rhode Island designated as an Enterprise 
Community under Title XIII of the Omnibus Budget Reconciliation Act of 1993. The Enterprise Community in Providence has a population of 48758 and includes portions of 11 of the city's 15 wards. It covers 13 census tracts and encompasses eight neighborhoods. This area of the city suffers from pervasive poverty and includes sizeable populations of Hispanic, Asian, and Black/African American residents. The Enterprise Community is also home to large numbers of recent immigrants, and approximately $60 \%$ of the people living there have limited proficiency in English. One daycare center serving medical staff from a major hospital was excluded from the study despite its location in the Enterprise Community, because the families it served did not reflect the demographics of the Enterprise Community.

From the results of focus group discussions and a preliminary survey of daycare centers, the Partnership concluded that the expense of purchasing booster seats constituted a significant obstacle for the low income target population. Consequently, the Partnership provided free booster seats to all parents participating in the study conditional upon the parent completing an hour long training session.

The Partnership developed a new, self contained, interactive curriculum that contained activities for parents and worksheets and songs for daycare staff to share with their students. Partnership staff followed two tracks in presenting the educational component. In one, they trained daycare staff to use the curriculum with the children at the center. The other track involved educating parents directly about the need to use booster seats. This training reported the risks to children of riding in automobiles without proper restraints and then described the types of booster seats and the children for whom they were appropriate. Educational materials were translated into the appropriate languages, and interpreters attended parent classes. In addition, parking lot signs purchased by the grant but installed by the Mayor's office reminded parents to use child restraints and described the characteristics of children who should ride in booster seats.

Additional interventions aimed at influencing parents were implemented at seven of the nine daycare centers. None of the nine daycare centers included statements about child restraints in their operating policies. Therefore, it was assumed that changing these policies would sensitize both staff and parents to the safety and liability issues. Staff, in particular, would be more likely to enforce state laws mandating the use of booster seats and have a powerful impact on parental behavior. First, an attorney and a representative from the Rhode Island Governor's Office on Highway Safety helped draft language dealing with traffic safety to be incorporated into the daycare center policies. The proposed policy stated the existing Rhode Island law-that all children under age 6 in a vehicle must be properly restrained in a child safety seat in the rear section of the vehicle and that children reaching 40 pounds should be restrained in a booster seat until they are at least 54 inches tall. The policy went on to state that parents must always have their children in a child safety seat when they are transported to and from the center and that anyone not abiding by this rule would be subject to a $\$ 50$ court fine (part of the existing state law). Several directors who reviewed the proposal felt that the language was too harsh and asked for an alternative policy. A more acceptable version that stated the law suggested that parents use child safety devices, and reminded them about the potential financial penalties, was accepted by seven of the daycare centers. The new policies were posted at the seven daycare centers and incorporated into their parent manuals. Some centers explained the contents to parents in detail, while others simply distributed their manuals to parents.
Financial incentives for using booster seats were offered to parents in four centers randomly selected from the seven daycare centers whose policies were modified. The small financial incentive reminded parents of the importance of using booster seats to protect their children. Unannounced Partnership staff who had trained the parents and staff visited each of the four centers on one afternoon and awarded \$10 gift certificates for the local grocery store to parents observed using a booster seat.

The dependent measure was the percent of children aged 4-8 observed riding in booster seats. It was expected that the provision of free booster seats accompanied with education would increase the number of 4-8 year olds restrained in booster seats. Bolstering the intervention first by changing daycare center policies regarding use of booster seats and then by adding financial incentives for using booster seats was hypothesized to produce greater use of booster seats.

Baseline observations of child restraint use at each daycare center were conducted shortly after the beginning of the school year. All observations were conducted in the afternoon at pick-up times under the assumption that parents tended to be less rushed when picking up their children than in the morning when dropping them off on the way to work. Observations were conducted by Partnership staff and students recruited from local colleges. The program evaluators developed a training manual, delivered a 30 minute training, and developed standardized data collection sheets. Bilingual observers were employed at sites serving large numbers of non-English speaking parents. Observers equipped with orange reflective safety vests carried a clipboard with a readily visible label on the back that read Traffic Survey. Observers approached each automobile after parents had settled their children and were about to drive away. The observer requested permission of the driver to ask a few questions and then read the required questions (for example, the age and weight of the child) while observing the use of restraints by the children. The entire interaction typically took less than two minutes.

Implementation of the interventions proved far more challenging than anticipated. Despite the clear interest of daycare center staff, many centers had difficulty finding times when all of their staff would be present for training. Thus, the Partnership conducted multiple staff trainings at some centers. The offer of a free booster seat to parents was insufficient for many parents. Consequently, free food was added as an enticement, and eye catching flyers were distributed to parents by center staff, all targeted at parents of children between the ages of 4 and 8 . The initial supply of low backed booster seats was supplemented with a set of high backed booster seats that were suitable for installation in older automobiles not equipped with shoulder belts in the rear seat. In the end, roughly half of the parents at each of the nine daycare centers attended one of the trainings and received free booster seats.

Four to eight weeks after implementation of all interventions, the same observers used for the pre-test conducted another round of observations employing the same protocol used to gather baseline data. The observers appeared unannounced at each daycare center, observed for a single afternoon, and did not know which parents had been given booster seats and training.

\section{RESULTS}

\section{Baseline observations}

Baseline observations conducted at eight of the nine daycare centers validated the need for an intervention. The first column in table 1 shows that virtually none (only $3 \%$ ) of the 4-8 year olds picked up from the daycare centers were restrained in a booster seat. Over half of the children were 


\begin{tabular}{|c|c|c|}
\hline Restraint used & $\begin{array}{l}\text { Baseline } \\
(n=185)\end{array}$ & $\begin{array}{l}\text { Post-intervention } \\
\text { ( } n=147)\end{array}$ \\
\hline Booster seat & 3 & 38 \\
\hline Child safety seat & 1 & 3 \\
\hline Lap and shoulder belt & 21 & 26 \\
\hline Lap or shoulder only & 19 & 8 \\
\hline No restraint used & 56 & 26 \\
\hline
\end{tabular}

unrestrained, and the remainder were incorrectly restrained. In sum, nearly all children picked up from these eight daycare centers traveled at the elevated risk levels associated with either the absence of restraints or the incorrect use of restraints.

\section{Post-intervention observations}

Comparison of the baseline and post-intervention columns in table 1 shows the significant impact of the intervention four to eight weeks later on the use of restraints $\left(\chi^{2}=83.4 ; \mathrm{df}=4\right.$, $\mathrm{p}<0.01$ ). The number of children observed riding in a booster seat increased from $3 \%$ to $38 \%$, while the number of unrestrained children shrank from $56 \%$ to $26 \%$. But the increase in booster seat use varied dramatically by age. Table 2 shows that the percent of 4-5 year olds observed riding in booster seats increased from 5\% to $63 \%$. For 6 year olds, the increase was much less: from $2 \%$ to $19 \%$. Not one 7 or 8 year old was observed riding in a booster seat before or after the intervention.

Examination of table 2 suggests that the intervention affected parents differently depending on the age of their children. Parents of 4-5 year olds tended to move their children into booster seats after the intervention. Parents of older children were more likely to restrain their children after the intervention than before, but they tended to restrain their 7 and 8 year olds with adult seatbelts, rather than utilizing booster seats.

There were neither enough participating daycare centers nor 4-8 year-old children in the study to effectively compare different types of interventions aimed at increasing booster seat use. Therefore, the analysis of post-test observations by level of intervention shown in table 3 is merely suggestive. Roughly $60 \%$ of children aged $4-5$ years old were observed riding in booster seats after the interventions, regardless of which level they received.

Thus, the education only level produced nearly as much booster seat use with 4 and 5 year olds as did the education and policy level, a level expected to be much more powerful than education alone. Adding financial incentives to education and policy changes yielded no subsequent improvement.
Table 3 Observed use of restraints (\%) post-intervention by condition and age of child

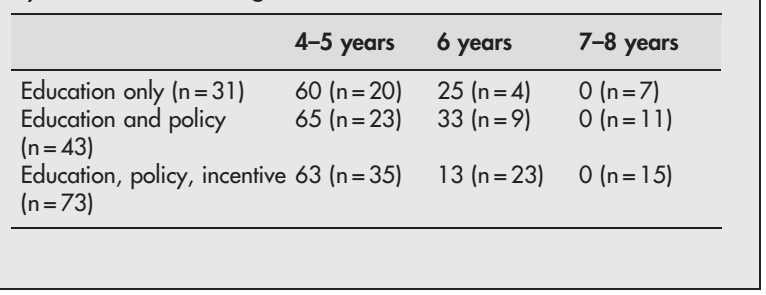

\section{DISCUSSION}

The results produced three important and clear findings. The most important showed that the number of unrestrained children dropped dramatically from 56\% before the intervention to $26 \%$ several weeks after the intervention, while the rate of booster seat usage increased from $3 \%$ to $38 \%$. These changes occurred in a low income, urban population using daycare centers and followed provision of a free booster seat accompanied by an educational session.

A second key finding replicated previous research showing a decrease in booster seat use with age. Many 4 and 5 year olds rode in booster seats after the interventions, but there were few 6 year olds and no 7 or 8 year olds observed riding in booster seats. This finding does not reflect parental disregard for the safety of their children. Rather, many parents of the older children chose to restrain their children in adult seatbelts. Parents of older children may have seen no need for the free booster seats and training after moving their children to adult seatbelts.

The third key finding is that three levels of the intervention produced nearly equivalent increases in booster seat use. The education and policy level was expected to be more effective than the education only level. Yet there was no difference in the results of the two levels. Adding financial incentives on top of changing center policies did not have the expected greater impact. Perhaps many of these parents did not need to be persuaded to use restraints-they simply needed to learn what to use and then to be given easy access to the proper safety device.

Would these parents have purchased booster seats on their own after learning about the importance of restraining 4-8 year olds in booster seats? Anecdotal evidence suggests not. The Governor's Office on Highway Safety in Rhode Island offers free child safety seat check-ups in the areas where the study was conducted. Technicians conducting these checkups rarely encounter newly purchased child safety seats and report having to replace most seats seen in the check-ups because of their poor condition. Parents who cannot afford new child safety seats probably would not purchase booster seats.

Parents who place their children prematurely in adult seatbelts may be an especially difficult population for efforts to increase booster seat use. Confident that their children are

Table 2 Observed use of restraints (\%) at baseline and post-intervention by age of child

\begin{tabular}{|c|c|c|c|c|c|c|}
\hline & \multicolumn{2}{|c|}{$4-5$ years } & \multicolumn{2}{|l|}{6 years } & \multicolumn{2}{|c|}{$7-8$ years } \\
\hline & $\begin{array}{l}\text { Before } \\
(n=84)\end{array}$ & $\begin{array}{l}\text { After } \\
(n=78)\end{array}$ & $\begin{array}{l}\text { Before } \\
(n=42)\end{array}$ & $\begin{array}{l}\text { After } \\
(n=36)\end{array}$ & $\begin{array}{l}\text { Before } \\
(n=59)\end{array}$ & $\begin{array}{l}\text { After } \\
(n=33)\end{array}$ \\
\hline Booster seat & 5 & 63 & 2 & 19 & 0 & 0 \\
\hline Child safety seat & 2 & 4 & 0 & 3 & 0 & 0 \\
\hline Lap and shoulder belt & 18 & 15 & 24 & 36 & 23 & 39 \\
\hline Lap or shoulder only & 21 & 5 & 17 & 6 & 17 & 15 \\
\hline No restraint used & 54 & 13 & 57 & 36 & 59 & 46 \\
\hline
\end{tabular}




\section{Key points}

- Before the intervention, $56 \%$ of $4-8$ year olds observed at eight daycare centers serving low income families in an urban area were observed using restraints, and only $3 \%$ rode in booster seats.

- Four to eight weeks after the intervention, $74 \%$ were restrained and $38 \%$ of observed children rode in booster seats.

- Changing center policies to recommend compliance with state restraint laws and an offer of financial incentives appeared to have no additional impact over providing free seats accompanied by training.

- Many 4 and 5 year olds rode in booster seats after the intervention, but there were few 6 year olds and no 7 or 8 year olds observed riding in booster seats.

- Restraint use with 6-8 year olds increased after the intervention, but the increase involved premature use of adult seatbelts.

safely restrained with adult seatbelts, these parents may be unaware of messages dealing with booster seats. Thus, prevention programs need to employ different interventions targeting parents who: (1) do not restrain their young children in vehicles versus (2) others who prematurely restrain their young children with adult seatbelts.

An unexpected finding bears on use of age, height, and weight in regulations specifying which children should ride in booster seats. Many parents did not know even the approximate height or weight of their children when asked by observers, but they knew their children's ages. Some parents may ignore recommendations based on height and weight simply because they do not know whether the recommendations apply to their children. Recommendations based on age avoid this potential for confusion. The trade-off is that age is a crude substitute for height and weight in assessing appropriate use of child restraints.

This exploratory study is encouraging and could serve as a model for other interventions, but the results are limited in their generalizeability. The study included low income parents from only one, relatively small urban area, all participating parents had placed their children in daycare centers, and observations of booster seat use occurred only at daycare centers and only at pick-up time. Even the use of observers wearing safety vests could have spurred some parents to restrain their children. The durability of the intervention's impact remains an open question. Postintervention observations taken four to eight weeks after the intervention should be a more accurate indicator of impact than if they had been made immediately after the intervention. Nevertheless, much longer follow up is necessary to ascertain the interventions' resilience. Finally, the absence of a no-intervention control group raises the possibility that some factor other than the intervention caused the increase in booster seat use. We are unaware of any such factor, such as a safety campaign or widely publicized crash resulting in serious injury to a child.

Finally, there are two reasons why the reported observations might underestimate the impact of providing booster seats and education to parents. First, only about half of the eligible parents received free booster seats and the required training. If we assume that all of the increase in observed booster seat use resulted from these parents, then roughly three quarters of these parents needed to begin using booster seats in order to produce the observed rate of $38 \%$ use of booster seats among all parents (including the half who did not receive booster seats). Second, low income parents may own fewer automobiles than more affluent parents and rely more on friends, relatives, and car pools to transport their children. Thus, some unrestrained children may have been riding with adults who did not insist upon restraints, even if the children's parents possessed a booster seat and required its use.

\section{ACKNOWLEDGEMENTS}

This project was supported by grant number DTNH22-97-H-05108 awarded to Scott Berns, MD by the National Highway Traffic Safety Administration (NHTSA) and by the Rhode Island Hospital Injury Prevention Center. Points of view in this document are those of the authors and do not necessarily represent the official position or policies of NHTSA. The authors also thank Angela Ferrara and Antilliano Estrella for help delivering the education component of the intervention, David Schiapo for inspecting installed booster seats, and Sandra Del-Sesto and the staff at Initiatives for Human Development for help preparing the parent and daycare staff educational components.

This study was funded by a grant from the NHTSA and support from the Rhode Island Hospital Injury Prevention Center.

\section{Authors' affiliations}

R Apsler, Rhode Island Hospital Injury Prevention Center, Harvard Medical School

S W Formica, Social Science Research and Evaluation, Inc

A F Rosenthal, Rhode Island Hospital Injury Prevention Center

K Robinson, University of Vermont College of Medicine

\section{REFERENCES}

1 National Highway Traffic Safety Administration. Proper child safety seat use chart. Accessed from http://www.nhtsa.dot.gov/people/injury/childps/ 2003

2 Centers for Disease Control and Prevention. National child passenger safety. MMWR Morb Mortal Wkly Rep 1999;48:83-4.

3 Committee on Injury and Poison Prevention. Selecting and using the most appropriate car safety seats for growing children: guidelines for counseling parents. Pediatrics 2002;109:550-3.

4 National Safe Kids Campaign. Accessed from http://www.safekids.org 2003.

5 Winston FK, Durbin DR, Bhatia E, et al. Patterns of inappropriate restraint for children in crashes. Annual Proceedings of the Association of Advanced Automotive Medicine 1999;43:59-69.

6 Decina LE, Knoebel KY. Child safety seat misuse patterns in four states. Accid Anal Prev 1997;29:125-32.

7 Durbin DR, Kallan MJ, Winston FK. Trends in booster seat use among young children in crashes. Pediatrics 2001;108:E109.

8 Motor-vehicle occupant fatalities and restraint use among children aged 4-8 years in the United States 1994-1998. MMWR Morb Mortal Wkly Rep 2000;49(7): 135-7

9 National Highway Traffic Safety Administration. A national strategy: increasing booster seat use for 4-to 8-year-old children. Washington, DC: NHTSA, 2002

10 Durbin DR, Elliott MR, Winston FK. Belt-positioning booster seats and reduction in risk injury among children in vehicle crashes. JAMA 2003;289:2835-40.

11 Ramsey A, Simpson E, Rivara F. Booster seats and reasons for nonuse. Pediatrics 2000; 106:E20.

12 Winston FK, Durbin DR, Kallan MJ, et al. The danger of premature graduation to seat belts for young children. Pediatrics 2000;105:1179-83.

13 Rivara FP, Bennett E, Crispin K, et al. Booster seats for child passengers: lessons for increasing their use. Inj Prev 2001;7:210-13.

14 Simpson EM, Moll EK, Kassam-Adams N, et al. Barriers to booster seat use and strategies to increase their use. Pediatrics 2002;110:729-36.

15 Chang A, Dillman AS, Leonard E, et al. Teaching car passenger safety to preschool children. Pediatrics 1985;76:425-8.

16 Arneson SW, Triplett JL. Riding with Bucklebear: an automobile safety program for preschoolers. J Pediatr Nurs 1990;5:115-22.

17 Roberts MC, Fanurik D. Rewarding elementary schoolchildren for their use of safety belts. Health Psychol 1986;5:185-96.

18 Foss R. Evaluation of a community-wide incentive program to promote safety restraint use. Am J Public Health 1989;79:304-6.

19 Stuy M, Green M, Doll J. Child care centers: a community resource for injury prevention. J Dev Behav Pediatr 1993;14:224-9.

20 Pless IB, Stulginskas J, Zvagulis I. Observed effects of media campaigns on restraint use. Can J Public Health 1986;77:28-32.

21 Ebel BE, Koepsell TD, Bennett EE, Rivara FP. Use of booster seats in motor vehicles following a community campaign: a controlled trial. JAMA 2003;289:879-84. 